\title{
Evaluation of Self Medication among Students from Different Universities in Chittagong, Bangladesh
}

\author{
JAKARIA $M,{ }^{1}$ HASANT $A,{ }^{1}$ TAREK MI ${ }^{1}$ ISLAM MZ,${ }^{1}$ ZAMAN R, ${ }^{1}$ PARVEZ $M,{ }^{1}$ CHOWDHURY TA, ${ }^{1}$ HASAN MI ${ }^{1}$ \\ SAYEED MA, ${ }^{2}$ ALI MH ${ }^{3}$
}

\begin{abstract}
Objective: We aimed to find out frequency of self medication among university students of Chittagong, Bangladesh by using a cross sectional questionnaire based survey study.

Method: For this study, 439 students selected from nine universities of Chittagong through non-probability convenience sampling.

Results:Among the total respondents, 278(63.32\%) respondents were males and I6I(36.67\%) respondents were females. The most important reasons for self medication were no need to visit doctor for minor illness 227(5I.70\%) and quick relief 16I(36.67\%). Among the total respondents, 229(52.16\%) used same direction of self medication of him/her for their family. The highest proportion of respondents $229(52.16 \%)$ did not check expiry date of medicine when they buy medicine from retail pharmacy. There were several conditions they had used self medications and the greatest number of students used to treat headache 273(62.18\%) and fever 199(45.33\%). The data reveals that the highest proportion, 243(55.35\%) students learned medications from doctor prescription provided to cure their previous illness. The greatest number of students 398(90.66\%) chooses allopathic medicine among four different system of medicine. The respondents used different allopathic drugs used in self medications where greatest number 296(67.42\%) used analgesics.

Conclusion: This study revealed that the prevalence and practices of self-medication among the university student and the greater part of students had a poor knowledge about proper self-medication whereas the knowledge of the benefits and risks were not adequate.
\end{abstract}

Keywords: Frequency, self-medication, university students, questionnaire.

\section{Introduction}

A medication (a medicinal product) may be defined as a product that contains a compound with established biological effects, plus excipients or excipients only; it may also have contaminants; the active compound is typically a drug or prodrug, but may be a cellular element. ${ }^{1}$ A drug is a curative agent; any substance other than food intended to affect the structure or function of a physiological system such as the human body and used in the prevention, diagnosis, alleviation, treatment or cure of disease in man or animals. ${ }^{2}$

1. Graduate Pharmacist, Department of Pharmacy, International Islamic University Chittagong (IIUC), Chawkbazar, Chittagong 4203, Bangladesh

2. Assistant Professor, \& Chairman, Department of Pharmacy, International Islamic University Chittagong (IIUC), Chawkbazar, Chittagong 4203, Bangladesh

3. Lecturer, Department of Pharmacy, International Islamic University Chittagong (IIUC), Chawkbazar, Chittagong 4203, Bangladesh

Corresponding author: Md. Jakaria, Department of Pharmacy, International Islamic University Chittagong (IIUC). 109, Chatteswary Road, Chawkbazar, Chittagong 4203, Bangladesh. Cell: 008801823618436; Email: pharmajakaria@rocketmail.com.
The hypothesis of self medication began appearing in medical journals in the 1970 s, as clinicians noticed that heroin addicts were using the drug to cope with problems such as stress and loneliness. This lead to the idea that drug using develops as a way of coping with stress in the absence of adequate solutions and meaningful social relationships. WHO states, self medication as element of the self care that helps efficient use of the burdened health care system with guidelines for the regulatory assessment of therapeutic products for use in self-medication. ${ }^{3-5}$ Self-medication is the act of procurement and consumption of pharmaceuticals without consulting medical practitioner. ${ }^{6}$ Alternative way self-medication can be defined as obtaining and consuming drugs without the advice of a physician either for diagnosis, prescription or surveillance of treatment. ${ }^{7}$ It may include the use of herbs, the retention and re-use of prescription drugs or the direct purchase of prescription-only drugs without medical input. ${ }^{8}$

The self medication theory reinforces the disease model of addiction. It runs the risk of simplifying the complex issue of addiction, which involves many psychological and social 
factors, to pure physiology. ${ }^{9-12}$ The concept of self medication which encourages an individual to look after minor ailments with simple and effective remedies has been adopted worldwide. ${ }^{13}$

Several medications have reportedly been used for this practice. This included antibiotics, analgesics and vitamins, analgesics, vitamins and oral antibiotics among primary care patients, while for OTC drugs; the commonly requested were for nervous system, analgesics, cough or cold medications. ${ }^{14}$

There are several benefits of self medication and these are, product safety when used as recommended in the instructions; acceptable risk, even when used for a longer duration, at a higher dose, or somewhat differently than recommended in the instructions; wider availability of medicines; greater choice of treatment; direct, rapid access to treatment; an active role in his or her own health care; self-reliance in preventing or relieving minor symptoms or conditions; educational opportunities on specific health issues (i.e. stop-smoking aids and products to treat heartburn); convenience; economy, particularly since medical consultations will be reduced or avoided. ${ }^{15}$

The overall aim of the study was to illustrate the selfmedication practices among Bangladeshi student studying in different universities located in Chittagong. Specifically, the aims of this study were:

- To find out the frequency of self medication among the students in selected university students,

- To find out the reasons for not consulting the doctor \& common problems for which students rely on self medication, and

- To increase awareness about the damaging effects of self medication.

\section{Study Methodology \\ Study site}

The survey study site was different universities located in Chittagong district. Chittagong is called the second largest city of Bangladesh. It is a part of the Chittagong Division ${ }^{16}$ and it is the largest sea port of Bangladesh. There are different public and private Universities located in this district. Nine universities named International Islamic University Chittagong (IIUC), Chittagong University (CU), Chittagong University of Engineering and Technology (CUET), Chittagong Veterinary and Animal Science University (CVASU), University of Science and Technology Chittagong (USTC), Southern University
Bangladesh (SUB), Port City International University (PCIU), University of Information Technology and Science (UITS) and BGC Trust University Bangladesh, were selected for survey study.

\section{Study design and data collection}

Questionnaire survey based, cross-sectional study ${ }^{17}$ was conducted in the different University located in Chittagong district in November-December, 2014. For this purpose, a self designed standard questionnaire was developed by the principle investigator, Md. Jakaria, final year project student of B. Pharm(Hons) under his supervisor Mohammed Abu Sayeed, Head and Assistant Professor, Department of Pharmacy, International Islamic University Chittagong (IIUC). The questionnaire contained some basic variables: University name, location and department, age and sex of students and some important questions in questionnaire were as follows:

Q 1. What is the reason for self medications?

Q 2. Do you use same prescription for your family?

Q 3. Do you check expiry date of medicine?

Q 4. In which condition do you use self medication?

Q 5. What are the sources of information about the drug?

Q 6. Which type of medicine do you use?

Q 7. Which type of allopathic drug do you use for self medications?

Four (04) students of the Bachelor of Pharmacy (B. Pharm) in the Department of Pharmacy of International Islamic University Chittagong (IIUC) were assigned for conducting this health survey. Each student was said to collect data from respondents, therefore the sample size was 439 . The data collectors were waiting in front of the class room during data collection session. Data were collected from the students of different age, sex, semester, department in a university. Each investigator analyzed the data individually and submitted the report to the principle investigator. The principle investigator then accumulated all the data.

\section{Sample size calculation and Statistical analysis}

In this regard, descriptive statistics were applied. Calculate the collected data by using Microsoft Excel 2003 and 95\% confidence interval calculated by using online calculator, calculator.net. Results were finally expressed graphically in percentages. 


\section{Results}

\section{Baseline characteristics of participants}

Among the total 439 respondents, 278(63.32\%) were male and $161(36.67 \%)$ were female (Fig. 1). The age of male and female students 18-24 years old. No questionnaires were under exclusion criteria that means all questionnaires were considered for calculation. The greatest male respondents (42) were from Chittagong University of Engineering and Technology (CUET), and female 50 respondents from International Islamic University Chittagong (IIUC).

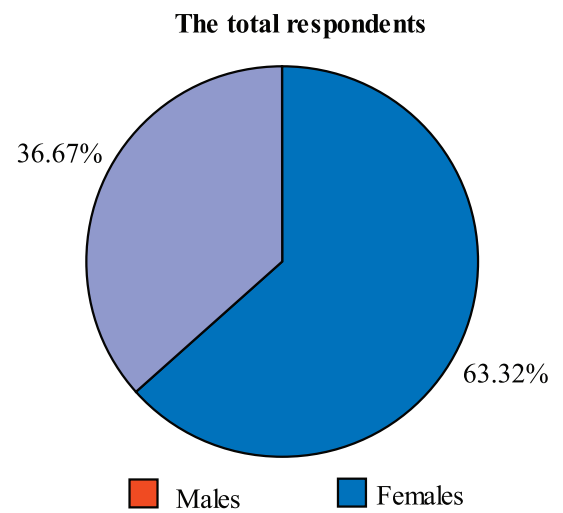

Fig.1: The total male and female respondents'responses to questionnaire

\section{Prevalent reason for self medications}

The male and female respondents perceived several advantages of self medication. The most important reasons were no need to visit doctor for minor illness $227(51.70 \%$ ), quick relief $161(36.67 \%)$ and time saving opportunity 63(14.35\%) (Table-I).

Table-I

Merits of self-medication stated by respondents

\begin{tabular}{lcc}
\hline Reason & Respondents \% & $95 \%$ CI \\
\hline Time-saving & $63(14.35 \%)$ & $14.35 \pm 3.28$ \\
No need to visit doctor for & $227(51.70 \%)$ & $51.70 \pm 4.68$ \\
minor illness & & \\
Economical & $27(12.98 \%)$ & $12.98 \pm 2.52$ \\
Quick relief & $161(36.67 \%)$ & $36.67 \pm 4.51$ \\
Ease and convenience & $37(8.42 \%)$ & $8.42 \pm 2.91$ \\
Crowd avoidance & $08(1.82 \%)$ & $1.82 \pm 1.4$ \\
Believe in Alternative & $11(2.50 \%)$ & $2.50 \pm 1.64$ \\
medicines (Unani/ & & \\
Ayurveda/ Homeopathy etc.) & \\
\hline
\end{tabular}

$95 \% \mathrm{CI}=95 \%$ Confidence Interval

\section{Same direction use for family}

From the total respondents, 229(52.16\%) used same direction of self medication of him/her for their family and rest $210(47.83 \%)$ had not used same direction of self medication of him/her for their family (Fig. 2).

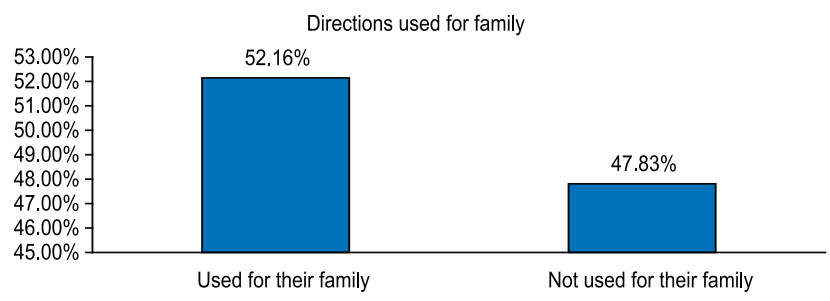

Fig.-2 Respondents using same directions of self medications used for family

\section{Checking expiry date of medicine}

The highest proportion of respondents, 229(52.16\%) did not check expiry date of medicine when buying from retail pharmacy and rest 61(13.89\%) did checked (Fig. 3).

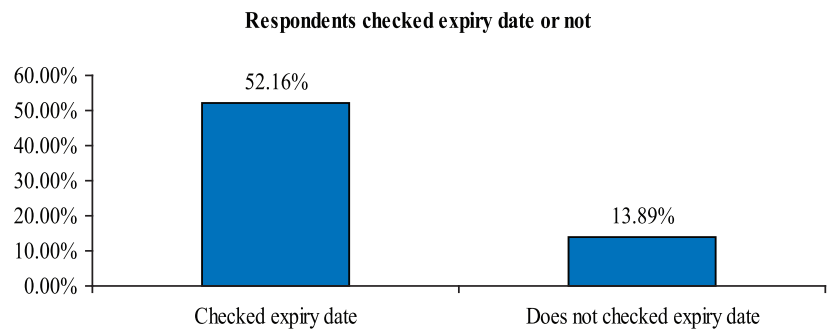

Fig.-3: Respondents checking expiry date of medicine or not

\section{Conditions of using self medications}

There were several conditions where they used self medications. The male and female respondents perceived several advantages of self medication. The greatest number of students used to treat headache $273(62.18 \%) \&$ fever 199(45.33\%) (Table-II).

Table-II

Conditions of using self medication

\begin{tabular}{lcc}
\hline Conditions & Respondents (\%) & $95 \%$ CI \\
\hline Headache & $273(62.18 \%)$ & $62.18 \pm 4.54$ \\
Cough, cold, sore throat & $157(35.76 \%)$ & $35.76 \pm 4.48$ \\
Stomach ache & $51(11.61 \%)$ & $11.61 \pm 3$ \\
Fever & $199(45.33 \%)$ & $45.33 \pm 4.66$ \\
Vomiting & $75(17.08 \%)$ & $17.08 \pm 3.52$ \\
Skin symptoms & $12(2.73 \%)$ & $2.73 \pm 1.52$ \\
Eye symptoms & $11(2.50 \%)$ & $2.50 \pm 1.46$ \\
Ear symptoms & $7(1.59 \%)$ & $1.59 \pm 1.17$ \\
Diarrhea & $103(23.46 \%)$ & $23.46 \pm 3.96$ \\
Helminthes & $48(10.93 \%)$ & $10.93 \pm 2.92$ \\
\hline
\end{tabular}


Table-III

The sources of information about drugs used in self medication

\begin{tabular}{lcc}
\hline Sources of information & Respondents (\%) & $95 \%$ CI \\
\hline Doctors' prescriptions & $243(55.35 \%)$ & $55.35 \pm 4.65$ \\
provided during prior illness & \\
Friends & $47(10.70 \%)$ & $10.70 \pm 2.89$ \\
Parents & $105(23.91 \%)$ & $23.91 \pm 3.99$ \\
Pharmacist & $71(16.17 \%)$ & $16.17 \pm 3.44$ \\
Advertisements & $19(4.32 \%)$ & $4.32 \pm 1.9$ \\
Books & $48(10.93 \%)$ & $10.93 \pm 2.85$ \\
Internet & $82(18.67 \%)$ & $18.67 \pm 3.65$ \\
\hline
\end{tabular}

$95 \% \mathrm{CI}=95 \%$ Confidence Interval

\section{Sources of drug information}

The data reveals that 243(55.35\%) students learned medications from doctor prescription provided during their previous illness. The information from parents, internet and pharmacist were 105(23.91\%), 82(18.67\%) and 71(16.17\%) respectively (Table-III).

\section{Type of medicine used in self medication}

From four types of medicine such as allopathic, homeopathic, unani and ayurvedic medicine, the greatest number of students, 398(90.66\%) choose allopathic medicine. (Table IV).

Table-IV

Type of medicines

\begin{tabular}{lcc}
\hline Type of medicine & Respondents (\%) & $95 \%$ CI \\
\hline Allopathic system & $398(90.66 \%)$ & $90.66 \pm 2.72$ \\
Homeopathic & $37(8.42 \%)$ & $8.42 \pm 2.6$ \\
Unani & $10(2.27 \%)$ & $2.27 \pm 1.39$ \\
Ayurvedic & $12(2.73 \%)$ & $2.73 \pm 1.52$ \\
\hline
\end{tabular}

$95 \% \mathrm{CI}=95 \%$ Confidence Interval

\section{Type of allopathic drug used in self medication}

The respondents used different allopathic drugs used in self medications. The highest percentages of respondents, $296(67.42 \%)$ used analgesics such as, paracetamol, aspirin, diclofenac etc., 142(32.34\%) used cough syrup and $137(31.20 \%)$ used $\mathrm{H}_{2}$ blocker or proton pump inhibitor (Table V).
Table-V

Different types of allopathic drugs

\begin{tabular}{lcc}
\hline Type of allopathic drug & Respondents (\%) & $95 \%$ CI \\
\hline Analgesic (Paracetamol & $296(67.42 \%)$ & $67.42 \pm 4.38$ \\
Aspirin, Diclofenac etc.) & & \\
Antibiotic & $72(16.40 \%)$ & $16.40 \pm 3.46$ \\
$\mathrm{H}_{2}$ Blocker/PPI & $137(31.20 \%)$ & $31.20 \pm 4.33$ \\
Antihistamine & $35(7.39 \%)$ & $7.39 \pm 2.45$ \\
Cough syrup & $142(32.34 \%)$ & $32.34 \pm 4.38$ \\
Vitamins & $72(16.40 \%)$ & $16.40 \pm 4.38$ \\
Anthelmintic & $192(43.73 \%)$ & $43.13 \pm 4.38$ \\
Laxative & $3(0.68 \%)$ & $0.68 \pm 0.8$ \\
Antiemetic & $8(1.82 \%)$ & $1.82 \pm 1.25$ \\
\hline
\end{tabular}

$95 \% \mathrm{CI}=95 \%$ Confidence Interval

\section{Discussion}

Self-medication is management of common health problems with medicines without therapeutic supervision. Different studies have been reported that the practice of selfmedication among university students from several countries. The present study was to assess their knowledge level and practices pattern regarding self-medication. A recent study with similar aims reported that $76 \%$ of the university students self medicate. It was among the first published estimate on the self medication among students. ${ }^{18}$ On the other hand, frequency of self reported medication is highly variable in different parts of the world; as low as $45 \%$ in Turkey to as high as 94\% in Hong Kong. ${ }^{19,20}$

The National Coordinating Council for Medication Error Reporting and Prevention states that "medication error as any preventable incident that may cause or lead to wrong medication use or patient harm, while the medication is in the control of the healthcare professional, patient or consumer. Such events may be related to professional practice, healthcare products, procedures and systems, including prescribing; order communication; product labeling, packaging and nomenclature; compounding; dispensing; distribution; administration; education; monitoring and use". ${ }^{21}$ In this study, students were taken self medications and according to the definition of National Coordinating Council, it was a medication error.

Self medication was common practices because of lack of proper functions of retail pharmacist, poverty, ignorance, misbelieves, patient acceptability with lack of awareness, lack of proper knowledge's towards health hazardous of self medication, extensive advertisement and availability of 
drugs, to maintained business policy of pharmaceutical company, improper monitoring system of manufacturing and dispensing of drugs, improper utilization of established law etc.

These are self-medication has a number of potential risks such as incorrect self-diagnosis; failure to seek appropriate medical advice promptly; incorrect choice of therapy; failure to recognize special pharmacological risks; rare but severe adverse effects; failure to recognize or self-diagnose contraindications, interactions, warnings and precautions; failure to recognize that the same active substance is already being taken under a different name, failure to report current self-medication to the prescribing physician (risk of double medication or harmful interaction); failure to recognize or report adverse drug reactions; incorrect route or manner of administration; inadequate or excessive dosage; prolonged use; risk of dependence and abuse; risks of food and drug interactions; storage in incorrect conditions or beyond the recommended shelf-life. At the community level, improper self-medication could result in an increase in drug-induced disease and in wasteful public expenditure.

The practice of self-medication was terrifyingly high among Bangladeshi students irrespective of their gender and knowledge about the use of medicines. Thus, to avoid or minimize the dangers of self medication, firstly the students should be educated about the dangers of indiscriminate use of drugs, public and private organizations should be take steps to generate the knowledge of dangers through mass media, campaign etc., secondly, the regulatory authorities must be updated their established law and implement on retail pharmacy and finally, a proper statutory drug control must be ensured and every retail pharmacy should be run by registered retail pharmacist. The authors also think that lack of good health services at study centers is also one of the prevalent reasons of self medication. At the same time lack of sufficient money to go and consult to doctor may be another reason for self medication however the data results are contrary to the presumed results. The above measures would definitely reduce the incidence of drug-related misfortunes and help in maintaining good health of the individual and society also.

\section{Conclusion}

From our evaluation, this questionnaire based study revealed that the prevalence and practices of self-medication among the university students and the majority of students had a poor knowledge about proper self-medication whereas the knowledge of the benefits and risks were not adequate. This study has also opened gateways for additional research in this concern, besides showing that it is a real problem and should not be ignored.

\section{Conflict of interest: None.}

Ethical Clearance: The protocol was approved by Planning and Development Committee (Grant No. Pharmacy P\&D 68/09-15), Department of Pharmacy, International Islamic University Chittagong, Chittagong 4203, Bangladesh.

\section{Source of Funding: None.}

\section{Acknowledgement}

The authors greatly acknowledge to the people those were directly or indirectly help us and appreciate our study. The authors also acknowledge to the faculty members of the Department of Pharmacy, International Islamic University Chittagong (IIUC).

\section{References}

1. Aronson JK. Medication errors: what they are, how they happen, and how to avoid them. Q J Med 2009;102: 513-521.

2. Jakaria M, Tarek MI, Hasanat A, Kamal ATMM, Sayeed MA and Ali MH. Banned Drugs Still Available in Bangladesh after the Declaration of the Regulatory Authority: A Cross Sectional Study Conducted in Chittagong City. International Journal of Public Health Research 2015;3(3):83-87.

3. Shah SJ, Ahmad H, Rehan RB, Najeeb S, Mumtaz M and Jilani MH. Self-medication with antibiotics among nonmedical university students of Karachi: a cross-sectional study. BMC Pharmacology and Toxicology 2014;15:74.

4. Kanthe RU. Self medication, Doctors and marketing of OTC products. Asian Journal of Management Research 2010; 229-238.

5. Bennett PN and Brown MJ. Topics in drug therapy, Clinical pharmacology, Churchill Livingstone ( $9^{\text {th }}$ ed.). 2003:25-26.

6. Rabbani MS, Alam MZ, Farooq S and Kadir MM and Ragesh G. A Survey of Utilization of Medications without prescription among in different age groups. Int J Pharm Pharm Sci 2014;76-178.

7. Kulkarni DPK, Khan DM and Chandrasekhar DA. Self Medication Practices among urban slum dwellers in south Indian city. Int J Pharm Bio Sci. 2012;3(3):81-87.

8. Alghanim SA. Self-medication practice among patients in a public health care system. Eastern Mediterranean Health Journal 2011;17(5):409-416.

9. Grinspoon MD, Bakalar L and Marihuana J. The Forbidden Medicine. New Haven, CT: Yale University Press, 1997.

10. Kasten BP. "Self-medication with alcohol and drugs by persons with severe mental illness". Journal of the American Psychiatric Nurses Association 1999;5:80-87.

11. Khantzian EJ, Mack JE and Schatzberg AF. "Heroin use as an attempt to cope: clinical observations". Am J Psychiatry 1974;131:160-164. 
12. Khantzian EJ. "The self-medication hypothesis of addictive disorders: focus on heroin and cocaine dependence". Am J Psychiatry 1985;142:1259-1264.

13. Jain S, Malvi R and Purviya JK. Concept of Self Medication: A Review. International Journal of Pharmaceutical \& Biological Archives 2011;2(3):831-836.

14. Afolabi AO. Self Medication, Drug Dependency and SelfManaged Health Care- A Review, Public Health- Social and Behavioral Health, Prof. Jay Maddock (Ed.). ISBN: 978953-51-0620-3, InTech, 2012.

15. apps.who.int, http://apps.who.int/medicinedocs/en/d/ Js2218e/1.1.html Accessed, 20 April, 2015.

16. Jakaria M, Hasan M, Hossain MS, Hasanat A and Sayeed MA. A cross sectional survey on health and nutritional status among the people of Chittagong city corporation, Bangladesh. Prog Health Sci, 2015;5(1):116-119.
17. Shah SP and Praveen BN. Awareness of Oral Cancer in Rural Bangalore Population: A Questionnaire Based Study. International Journal of Scientific Study 2014; 1(6): 14-16.

18. Oshikoya KA, Idowu OS and Olisamedua FN. Selfmedication for infants with colic in Lagos, Nigeria. BMC Pediatrics 2009;9:1-8.

19. Sarahroodi S, Arzi A, Swalha AF and Ashtranezhad A. Antibiotic self medication among southern Iranian University Students. International J Pharmacol. 2010;6(1):48-52.

20. Nalini GK. Self medication among allopathic medical Doctor in Karnataka India. British J Med Prac. 2010;3(2):325.

21. Malhotra K, Goyal M, Walia R and Aslam S. Medication Errors: A Preventable Problem, Indian Journal of Clinical Practice 2012;23(1):17-21. 